\title{
Las movilidades y prácticas turísticas ¿criterios válidos para delimitar el Caribe continental? Reflexiones a partir del caso de Yucatán*
}

\begin{abstract}
Samuel Jouault
Afiliado institucionalmente a la Facultad de Ciencias Antropológicas de la Universidad Autónoma de Yucatán (México) e investigador Asociado al Centro de Estudios Mexicanos y centroamericanos (CEMCA - UMIFRE n¹6). Correo electrónico: sam.jouault@gmail.com. El autor es doctor en Geografía por la Universidad de Angers (Francia). ORCID ID: https://orcid.org/0000-0003-4419-900X. Recientemente ha publicado, entre otros: Tourisme et sociétés locales en Amérique latine: une approche «sentipensante» de l'agent de développement puis de l'universitaire, Confins, Año 2019 No. 39 y en coautoría (2019). "Pour une approche conjointe du tourisme et de la santé: postulats à partir de l'exemple de Cancún - Riviera Maya (Mexique)". Téoros Vol. 38 No. 2 (2019). Entre sus temas de interés se encuentran Turismo, globalización y sociedades locales.
\end{abstract}

Recibido: 2 de diciembre de 2018

Aprobado: 12 de marzo de 2019

Modificado: 1 de abril de 2019

Artículo de investigación científica

DOI: http://dx.doi.org/10.15648/hc.37.2020.4

Este artículo forma parte del proyecto "Representaciones literarias de insularidad en escritores de Yucatán, Belice y Guyana. Hacia un modelo para el Caribe continental (Conacyt CB257673)" financiado por el Consejo Nacional de Ciencia y Tecnología - CONACYT Ciencia Básica 2015 (México). Esta publicación está bajo una licencia Creative Commons Reconocimiento-NoComercial 4.0 
Las movilidades y prácticas turísticas ¿criterios válidos para delimitar el Caribe continental? Reflexiones a partir del caso de Yucatán

\title{
Resumen
}

En una escala mundial, las movilidades turísticas han aumentado exponencialmente desde la Segunda Guerra Mundial. La región caribeña es uno de los espacios más atractivos. Si bien el fenómeno turístico se concentraba en los litorales, desde hace aproximadamente una década las tierras interiores han comenzado un proceso de turistificación, patente en el Caribe continental y, de manera acelerada, en la Península de Yucatán. Este texto propone una reflexión acerca de la evolución de las definiciones y delimitaciones del Caribe contemporáneo a través de las prácticas y movilidades turísticas, enfatizando su carácter de criterios válidos para participar en estas nuevas aproximaciones.

Palabras clave: turistificación, traspaís, limite, México, Caribe.

Tourism mobilities and practices: are these valid criteria to delimit the continental Caribbean? Reflections from the Yucatan case

\begin{abstract}
On a global scale, tourism mobilities have increased exponentially since World War II. The Caribbean region is one of the most attractive places. Whilst the tourist phenomenon was previously focused on the coast, for about a decade the inland areas have become touristified, as evident in the Mainland Caribbean case, particularly the accelerated tourism in the Yucatan Peninsula. This article offers a reflection on the evolution of the definitions and delimitations for the contemporary Caribbean, and considers tourism practices and mobilities as valid criteria for generating new approaches in this field.
\end{abstract}

Keywords: touristification, hinterland, limit, Mexico, Caribbean.

As mobilidades e práticas turísticas, critérios validos para delimitar o Caribe continental? Reflexões sobre o caso de Yucatán

\section{Resumo}

52 A uma escala mundial, as mobilidades turísticas foram aumentando exponencialmente desde a segunda guerra mundial. A região do Caribe é um dos espaços mais atraentes. Se bem que o fenómeno turístico estava concentrado nos litorais, cerca 
de uma década, no interior das terras começou um processo de turistificação, como se mostra no caso evidente do Caribe continental, em particular a Península de Yucatán, marcada por uma turistificação acelerada. Este texto propõe uma reflexão sobre a evolução das definições e delimitações do Caribe contemporâneo através de práticas e mobilidades turísticas, enfatizando os critérios validos para participar em estas novas abordagens.

Palavras-chave: turistificação, interior, limite, México, Caribe.

\section{Les mobilités et les pratiques touristiques. Des critères valides pour délimiter le Caraïbe continental? Des réflexions à partir du cas de Yucatán}

\section{Résumé}

A l'échelle mondiale, les mobilités touristiques ont augmenté exponentiellement depuis la seconde guerre mondiale. La région caribéenne est un des espaces touristiques plus attractifs. Si bien le phénomène touristique se concentrait sur les littoraux il existe, depuis une dizaine d'années, une mise en tourisme des espaces ruraux au cœur de la Caraïbe continentale et de manière accélérée dans la péninsule du Yucatán. Ce texte propose une réflexion sur l'évolution des définitions et délimitations de la Caraibe contemporaine á travers les pratiques et mobilités touristiques en mettant l'emphase sur la validité des critères pour participer à ces nouvelles approximations.

Mot clés: mise en tourisme, arrière-pays, limite, Mexique, Caraibe.

\section{INTRODUCCIÓN}

Hace casi tres décadas, en 1989, Yolanda Wood escribió el texto "Repensar el Caribe"1, una respuesta ante el complejo y difícil problema de la delimitación del espacio Caribe y las diversas acepciones utilizadas históricamente como definición del término. La cuestión de los límites ocupa un lugar paradoxal en la geografía; no está ubicada como un concepto fundamental de la disciplina a diferencia del espacio, de la escala, del paisaje o del territorio. Se prefieren conceptos como discontinuidades, fronteras o fragmentaciones. Los límites del Caribe parecen

1 Yolanda Wood "Repensar el espacio Caribe", Revista de la Universidad de La Habana Nº 236 (1989): 67-80. 
muy sencillos a primera vista: el Caribe sería un conjunto de territorios, esencialmente insulares, bordados por el mar del mismo nombre, el mar Caribe. Detrás de esta simplicidad aparente, sin embargo, la aprehensión de este espacio regional resulta compleja pues las definiciones son muy variables y difieren según el autor y la especialidad (los ejemplos de Gaztambide-Geigel $^{2}$; Kempado ${ }^{3}$; Guarch-Delmonte ${ }^{4}$; Sheller ${ }^{5}$; Godard y $\operatorname{Hartog}^{6}$; Girvan ${ }^{7}$ lo evidencian).

Entonces, ¿qué es el Caribe? El Caribe es un mar enclavado entre dos continentes, el norteamericano y el sudamericano. El oeste y el este se podrían asimilar a dos estrechas franjas de tierra, istmo y archipiélago, que unirían las dos masas de la tierra emergidas. Evidentemente, las denominaciones «Mar Caribe» o «Región del Caribe» están henchidas de historia y expresan, del mismo modo, una realidad física. Sus límites son difusos y nítidos: esto será el centro de nuestra reflexión. Metodológicamente, abordamos esta problemática con un estado del arte que define las movilidades y prácticas turísticas, símbolos de una aproximación renovada de la geografia del turismo y sus implicaciones espaciales con la creación de nuevas territorialidades turísticas como los traspaíses ${ }^{8}$. Un trabajo de encuesta en campo permitió analizar la diversificación de la oferta turística a través de los actores turísticos, tejiendo traspaíses vinculados a los puertos del Caribe continental (análisis de la oferta de la industria del turismo de cruceros) junto a una revisión estadística de las frecuentaciones turísticas 9 . Justamente, la problemática principal

2 Antonio Gaztambide-Geigel, "La invención del Caribe en el Siglo XX. Las definiciones del Caribe como problema histórico y metodológico", Revista Mexicana del Caribe Nº 11 (1996): 75-96.

3 Kamala. Kempado, Sun, Sex and Gold, Tourism and Sex Work in the Caribbean (New York: Rowman \& Littlefield Publishers, 1999).

4 José Guarch-Delmonte, "The first Caribbean People", en General History of the Caribbean, Vol I. Autochtonous Societies, editado por J. Sued-Badillo (London: Unesco, 2003), 93-133.

5 Mimi Sheller, Consuming the Caribbean, from Arawaks to Zombies (London y New York: Routledge, 2003).

6 Henri Godard y Thierry Hartog, "Le bassin Caraïbe: Présentation”, Mappemonde, 724 (2003). http://www.mgm.fr/PUB/Mappemonde/Mappe403R.html (15 de febrero de 2018).

7 Norman Girvan, "Reinterpreting the Caribbean", en The Caribbean Economy, a reader, editado por Pantin (Kingston: Ian Randle Publishers, 2005).

8 El concepto de traspaís utilizado en esta propuesta se relaciona con las nociones de interior, margen y periferia, y se refiere a la región tierra adentro.

9 Organización Mundial del Turismo (OMT), Panorama OMT del Turismo Internacional, Departamento de publicaciones de la OMT, 2017. https:/ / www.e-unwto.org/doi/pdf/10.18111/9789284419043 (15 de enero de 2018). 
se centra en los aportes de una renovada aproximación geográfica al turismo: el turismo como prisma de observación de fenómenos sociales y campo de investigación privilegiado, la distinción entre turismo y tiempo libre, la dimensión espacial del turismo. Así, nos preguntamos, ¿en qué medida las movilidades y las prácticas turísticas son un criterio válido para delimitar y redefinir el espacio caribeño e incluir el Caribe continental?

Después de tratar en una primera parte al Caribe, sus definiciones y delimitaciones múltiples, abordaremos el turismo en el espacio caribeño - de un turismo de cruceros a la turistificación de los espacios rurales-. La nueva aproximación a una geografía del turismo permitirá definir tanto las movilidades y prácticas, como el proyecto turístico. La construcción del traspaís será abordada desde un anclaje teórico antes de proponer una lectura de la península basada en estos elementos de reflexión, en particular la turistificación de los espacios rurales.

\section{Del Caribe a los Caribes: definición y delimitaciones MÚLTIPLES}

El vocablo Caribe remite, en primer lugar, al mar del mismo nombre, elemento de continuidad en medio de un conjunto terrestre fragmentado, bien por bloques levantados o sumergidos, entre los cuales los pasos son escasos y difícilmente franqueables, bien por una serie de islas que marcan la vertiente oriental de esta masa líquida. Archipiélago, mar Caribe, ahí está el epicentro, la intensidad máxima del «Caribe», aunque no lo limita (Rodriguez ${ }^{10}$; Bégot y Buleon ${ }^{11}$ ). Varias acepciones del Caribe coexisten y podemos distinguir las siguientes:

- la definición hidrográfica, que considera al Caribe como una cuenca.

- la acepción geopolítica y cultural, que define la región como la del Caribe no hispánico y el Caribe sajón.

10 José Rodriguez, "Qu'est ce que la Caraibe? Vers une définition géographique", en Caribbean Atlas, editado por Cruse y Rhiney, 2013. http://www.caribbean-atlas.com/fr/thematiques/quest-ce-quela-caraibe/qu-est-ce-que-la-caraibe-vers-une-definition-geographique/.

11 Monique Bégot y Pascal Buleon, Una Cuenca en el Mundo en Atlas Caribe (Normandie: Universidad de Caen, 2017). http://atlas-caraibe.certic.unicaen.fr/es/theme-10.html (15 de diciembre de 2017). 
- la región histórica a partir de la noción de «pequeña Caribe», inspirada esencialmente en la economía de plantación.

- la definición geopolítica económica, que se nutre del concepto de «Gran Caribe» o «Gran cuenca caribeña».

- el Caribe oceanológico, que se basa en el principio de funcionamiento oceanográfico de la formación del gran mar interior. Al igual que en otros lugares del mundo, se ha hablado muchas veces de un Mediterráneo americano. Considerando la lectura que hizo del mar epónimo el historiador Fernand Braudel, y del concepto que se construyó merced a distintas aportaciones y debates, es interesante considerar al Caribe como uno de los Mediterráneos del mundo.

- la región cultural, que se apoya en el concepto de cultura caribeña; otro concepto de «Gran Caribe» como gran macro-región afro-latino-americana. El Caribe, según los círculos de filiación o de regionalización humana y antropológica, que se establece como área de diseminación de un ser humano de una filiación especial: el caribeño.

La región tiene límites variables y una superficie que se extiende en casi 4000 kilómetros (del extremo de Florida o de las costas de Yucatán a Venezuela) hasta el continente; desde Panamá hasta Puerto Rico o desde Cuba hasta Trinidad. Aunque las realidades son muy diversas, hay concurrencia en la historia, en la vida cotidiana y en la percepción del mundo que tienen sus habitantes. Desde las costas de Yucatán, ubicadas a menos de doscientos kilómetros del continente sudamericano, hasta Trinidad, situada a algo más de diez kilómetros, el archipiélago se extiende a lo largo de los cuatro mil kilómetros de un arco geográfico que une las dos masas continentales americanas. El Caribe es también el Golfo de México y las Guayanas, y su intensidad tiene resonancias en todas las costas, desde el río Grande hasta el Orinoco. Pese a ser la expresión de una realidad física, el Caribe es sobre todo un acontecer histórico y una cultura (Bégot y Buleon ${ }^{12}$; Godard y Hartog ${ }^{13}$ ).

\footnotetext{
12 Bégot y Buleon, Una Cuenca en el Mundo.

13 Godard y Hartog, "Bassin Caraibe".
} 
La originalidad física de la región se fundamenta igualmente en la existencia de tres de los más grandes ríos del mundo que alimentan las aguas marinas y crean turbulencias arcillosas que se encuentran hasta bien lejos en alta mar, mezcladas con las aguas saladas. El río Amazonas y la potente corriente que genera bordean las costas de las Guayanas y sus efectos se notan hasta la altura de Trinidad, donde el Orinoco deposita sus propios aluviones. Los manglares se extienden por todo el litoral bajo del continente sudamericano. En el norte, por el contrario, el delta del Misisipi acumula aluviones en los fondos marinos y provoca el importante avance de las tierras hacia el mar. Las costas del mar y de la cuenca del Caribe forman así una sucesión de largas franjas arenosas o de manglares interrumpidas por costas rocosas, frecuentemente originadas por volcanes ${ }^{14}$.

Si las definiciones del Caribe son múltiples, sus límites no son nítidos; la búsqueda revela que su existencia y su realidad se convierten en otras tantas evidencias. El Caribe continental, que pretendemos estudiar en esta propuesta, integrará los estados de la Península de Yucatán, y los países de América Central con costas y vistas hacia el mar Caribe, Colombia, Venezuela y las Guayanas.

\section{El TURISMO EN EL ESPACIO CARIBEÑO: LA SUPREMACÍA DEL CRUCERISTA}

Aproximarse a la región caribeña a través del prisma turístico no es neutral. Las estancias en los puertos caribeños han permitido observar los numerosos flujos vertidos por los cruceros parqueados (hasta cinco al día en Nassau, Bahamas o Cozumel, México) y entender que la problemática turística divide a los miembros de las sociedades locales.

Algunos apuntan hacia una economía ampliamente impactada por el turismo, otros hacia impactos socio-ambientales que tienden hacia los conflictos y, últimamente, unas voces apuestan por una industria cultural caribeña como nuevo imán turístico. El Caribe atrae a los turistas por el imaginario vinculado a las aguas cristalinas del Mar Caribe, las

14 Bégot y Buleon, Una Cuenca en el Mundo. 
playas de arena fina y clara bordadas por los cocoteros, un cielo asoleado y temperaturas clementes una gran parte del año. Este diferencial climático es un argumento importante para turistas norteamericanos, europeos y sudamericanos. En 2015, 38 millones de turistas llegaron a la región caribeña incluyendo a América Central, los estados de la Península de Yucatán, las Guayanas, Colombia y Venezuela. En 10 años, el aumento de $45 \%$ de la frecuentación de la región caribeña es sensiblemente superior a la evolución de la frecuentación turística mundial $\left(\mathrm{OMT}^{15}\right)$.

Así, el Caribe es, ante todo, el destino de los cruceristas -turistas que se embarcan en cruceros-; así, uno de cada dos cruceristas en el mundo escoge viajar en un espacio recorrido por más de 130 cruceros $^{16}$. Algunos destinos como la isla mexicana de Cozumel acogen más de 7000 cruceristas al día (un total anual de más de 2.5 millones): la presión sobre los territorios que acogen este tipo de turismo es muy fuerte. Dehoorne et al. ${ }^{17}$ señalan que la industria de los cruceros emergió en la primera mitad del siglo XX y evolucionó a partir de la década de 1970, dando origen a un turismo de masas específico. El barco es a la vez un medio de transporte y un destino. Las escalas tienen un papel secundario en esta lógica que privilegia el gigantismo, la estandarización y la uniformización. La industria del crucero está dominada por algunas grandes empresas y dos poderosas compañías se dividen un mercado construido alrededor de la demanda norteamericana: la Carnival Corporation (que incluye a Holland America Line, Costa Cruises, Cunard Line, Seabourn Cruise Line, Windstar Cruises y P\&O-Princess) ampliamente presente en el Caribe Continental (Figura 1) y la Royal Caribean Cruises lines.

15 OMT, 2017; Organización Mundial del Turismo (omt), Panorama OMT del Turismo Internacional. Departamento de publicaciones de la OMT, 2017. (fecha de consulta 6 de diciembre de 2017). https://www.e-unwto.org/doi/pdf/10.18111/9789284419043

16 Dehoorne, Olivier, Christelle. Murat y Nathalie Petit-Charles, "Le tourisme de croisière dans l'espace caribéen: évolutions récentes et enjeux de développement", Études caribéennes N ${ }^{\circ}$. 13-14 (2009). http://etudescaribeennes.revues.org/3843; DOI: 10.4000/etudescaribeennes.3843 (17 de diciembre de 2017).

17 Murat Dehoorne y Petit-Charles, "Tourisme de croisière"; Olivier Dehoorne y Nathalie Petit-Charles, "Tourisme de croisière et industrie de la croisière", Études caribéennes No. 18 (2011). http://journals.openedition.org/etudescaribeennes/5623 (17 de diciembre de 2017). 


\section{Figura 1}

Destinos y cruceros en el Caribe Continental en 2016

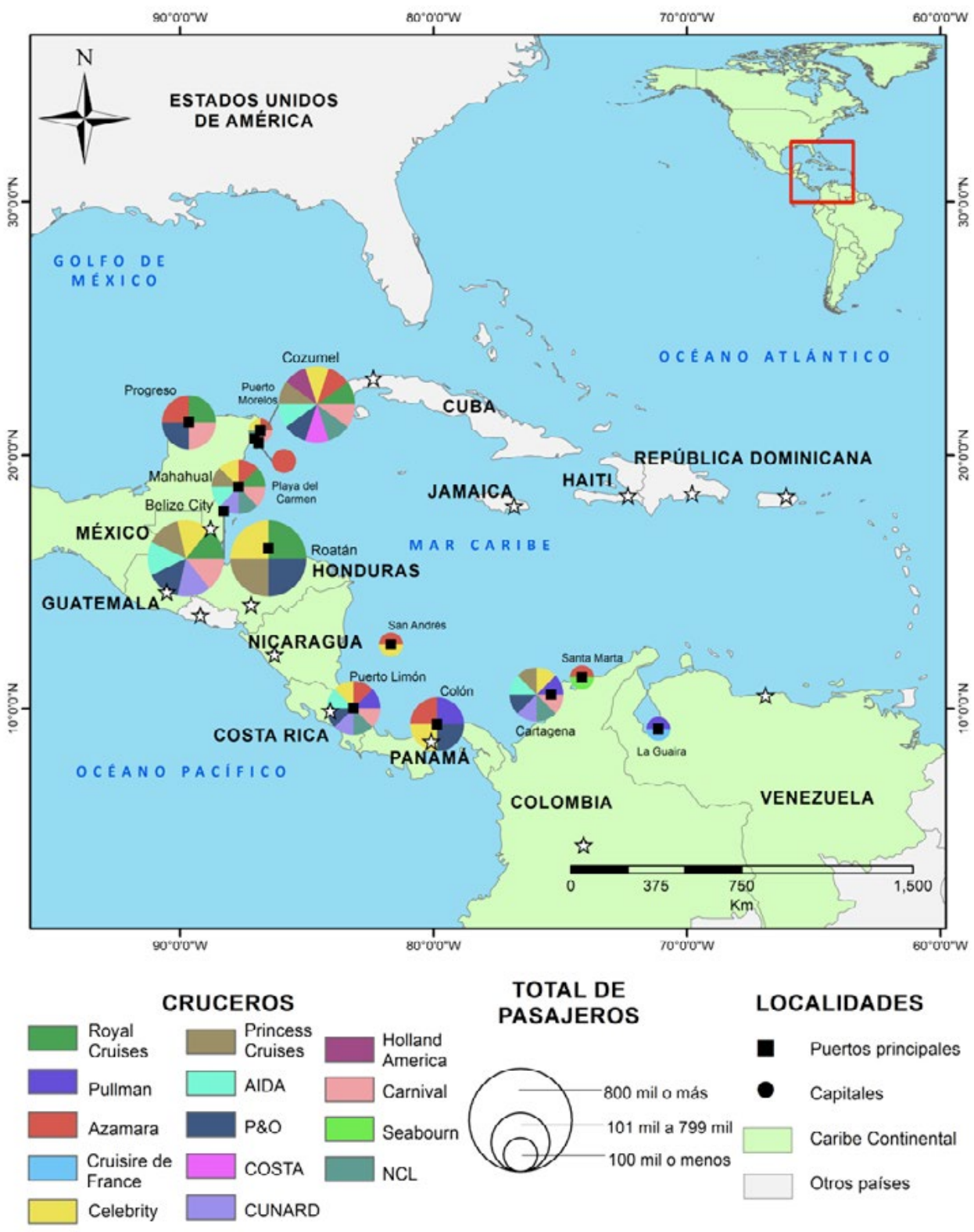

Fuente: Elaboración propia. Realización: Alejandro Montañez Giustinianovic. 
Mientras la mayoría de los cruceristas se quedan en el barco, otros bajan en el puerto-destino o en sus playas y algunos más se aventuran en los traspaíses, atrás de estos puertos. Son estos últimos turistas, así como sus proyectos, prácticas y movilidades, quienes nos interesan en esta propuesta. En sus movilidades, los turistas tienen proyectos y sus múltiples prácticas pueden clasificarse en tres vertientes: el descubrimiento, el descanso y cuidado del cuerpo, y el juego. Si en el Caribe el cuidado del cuerpo y el juego (tanto deportivos y de azar tales como los juegos de casino) son centrales, nuestra propuesta asume que numerosos turistas asocian el descanso y el cuidado del cuerpo con los espacios litorales, y el descubrimiento con los espacios rurales.

\section{De las movilidades y PRácticas turísticas al proyecto TURÍSTICO}

La práctica es la acción que se inscribe en un ambiente establecido. Esta actividad está dirigida a un propósito específico; lo que hace un individuo y el significado que le da a lo que hace ${ }^{18}$. Así, la práctica siempre se contextualiza de acuerdo con una situación, está estrechamente relacionada con una circunstancia determinada por un medio ambiente, y al mismo tiempo actúa sobre el medio ambiente y lo modifica ${ }^{19}$. Pascal Cuvelier $^{20}$ introdujo el concepto de la práctica en el estudio del turismo al definirlo como todos los actos que el individuo vive en un espacio de libertad, tratando de ponerles un significado y explicar lo que le hacen sentir. Resulta más apropiado el término práctica que el de consumo, ya que el primero abarca un conjunto de procesos y condiciones del universo turístico, mientras que el segundo solo contempla la conducta del intercambio de bienes y servicios de un mercado. Por lo tanto, las prácticas turísticas son acciones asociadas a un contexto temporal, fuera del lugar de residencia, desarrolladas durante el tiempo libre, y de carácter socio-cultural. Si bien cada turista tiene sus propias maneras de disfru-

18 Jacques Levy y Michel Lussault, Dictionnaire de la géographie et de l'espace des société (París: Belin, 2003).

$6019 \mathrm{Lu} \mathrm{Li}$, "Les pratiques touristiques des touristes francais en Chine" (tesis de doctorado, Université d' Angers, 2012).

20 Pascal Cuvelier, Anciennes et nouvelles formes de tourisme: une approche socio-économique (París: L' Hammatan, 1998). 
tar el lugar, muchos comparten una perspectiva global, haciendo que las prácticas turísticas a menudo sean compartidas por una población durante un período determinado, de modo que podemos clasificarlas en categorías ${ }^{21}$.

Urry $^{22}$ conceptualiza la práctica turística como una actividad vinculada al tiempo libre en oposición a un trabajo reglamentado y organizado. Se trata de una práctica de desplazamiento espacial de un lugar de residencia hacia otro durante períodos temporales breves. Las prácticas turísticas no tienen características en sí, sino que se definen por contraste respecto a las prácticas sociales cotidianas, no turísticas. Sin embargo, $\mathrm{Urry}^{23}$ precisa que el turista puede sentirse, por momentos, no tan alejado de las prácticas cotidianas. Textos más recientes del geógrafo francés Rémy Knafou y su equipo ${ }^{24}$, Equipo MIT $^{25}{ }^{26}$, conceptualizaron al turismo como un sistema producido a través de relaciones entre el turista, las prácticas y los lugares turísticos ${ }^{27}$. El equipo MIT coincide con Urry al definir las prácticas turísticas como los contrastes y diferencias entre los lugares del universo familiar y los lugares exóticos y desconocidos. En ellos, el turista experimenta la confrontación entre ambos lugares y estilos de vida, en donde se intenta buscar una identidad a través de la otredad o alteridad que provoca el destino ${ }^{28}$.

$21 \mathrm{Lu} \mathrm{Li}$, "Les pratiques touristiques des touristes français en Chine" (tesis de doctorado, Université d' Angers, 2012).

22 John Urry, The Tourist Gaze: Leisure and Travel in (Londres: Sage publications, 1990).

23 John Urry, The Tourist Gaze: Leisure and Travel in (Londres: Sage publications, 1990).

24 Rémy Knafou, Murielle Bruston, Florence Deprest, Philippe Duhamel, Jean-Christophe Gay y Isabelle Sacareau, "Une approche géographique du tourisme”, L’Espace Géographique 26-3 (1997): 193-204.

25 Traducción de «Mobilités Itinéraires, Tourismes».

26 Equipe MIT. La mise en tourisme des lieux: un outil de diagnostic. París: Belin, 2000. Equipe MIT. Tourismes 1. Lieux communs (París: Belin, 2002). Equipe MIT. Tourismes 2. Moments de lieux (París: Belin, 2005). Equipe MIT. Tourismes 3. La révolution durable (París: Belin, 2011).

27 Rémy Knafou y Mathis Stock, "Épistémologie de la géographie", en Dictionnaire de la géographie et de l'espace des sociétés, eds. J. Levy y M. Lussault (París: Belin, 2003), 323-325.

28 Gwendal Simon, Pratiques touristiques dans la métropole parisienne: une analyse des mouvements (París: Université Paris-Est, 2010). 
En este sentido, el turismo consiste en cambiar de lugar y enfrentarse a la alteridad ${ }^{29}$ : el desplazamiento turístico implica dejar voluntariamente el lugar donde uno vive para vivir temporalmente en otro lugar. Este otro lugar no se determina de forma aleatoria, sino por el deseo del turista de sentir la alteridad. Por lo tanto, un turista que busca relajación, bienestar físico y mental tiende a visitar lugares conocidos asociados a estas características, mientras los turistas que quieren descubrir diferentes paisajes y culturas tienden a elegir lugares cargados con mayor alteri$\mathrm{dad}^{30}$. En la literatura anglosajona la práctica turística es asociada con la movilidad que el turista realiza en los destinos; en dicha investigación ${ }^{31}$ la movilidad deriva en actividades de consumo del espacio y tiempo, es decir, la movilidad es capaz de atraer a muchas personas quienes consumirán un tiempo atractivo y placentero para ellas.

Dentro de las distintas definiciones de movilidades, encontramos las que la relacionan con la localización de las prácticas en un lugar distinto al de residencia ${ }^{32}$. El desplazamiento de un lugar a otro puede referirse a itinerarios entre lugares familiares y dentro del cotidiano, y el que nos concierne a nosotros, el movimiento entre el lugar de origen a los lugares de alteridad o no cotidianos (Tabla 1).

Tabla 1

La primera distinción: lugares cotidianos y lugares no cotidianos

\begin{tabular}{|l|l|l|}
\hline & \multicolumn{1}{|c|}{ Lugares cotidianos } & \multicolumn{1}{c|}{ Lugares no cotidianos } \\
\hline $\begin{array}{l}\text { Prácticas no rutinarias } \\
\text { (recreación) }\end{array}$ & $\begin{array}{l}\text { Prácticas vinculadas al tiempo } \\
\text { libre }\end{array}$ & Prácticas turísticas \\
\hline $\begin{array}{l}\text { Prácticas rutinarias } \\
\text { (trabajo) }\end{array}$ & $\begin{array}{l}\text { Desplazamientos recurrentes } \\
\text { (Trabajo, escuela, etc.) }\end{array}$ & $\begin{array}{l}\text { Viajes de trabajo, congresos, } \\
\text { conferencias etc. }\end{array}$ \\
\hline
\end{tabular}

Fuente: Stock, M., y P. Duhamel. "A practice-based approach to the conceptualisation of geographical mobility". Belgium Journal of Geography 1-2 (2004): 59-68.

29 Philippe Violier, “Tourisme et médias: regards d'un geografe”, Le Temps des Médias No. 8 (2007): 159-170.

30 Véronique Mondou, y Philippe Violier, Projets, pratiques et lieux touristiques, quelles relations? (Angers: Université d'Angers, 2004).

6231 Alan Lew y Bob McKercher. "Modeling turist movements, a local destination analysis", Annals of Tourism Research Vol. 33 N. 2 (2006): 403-423

32 Stock Mathis y Philippe Duhamel, "A practice-based approach to the conceptualisation of geographical mobility", Belgium Journal of Geography N 1-2 (2004): 59-68. 
Varios autores han diferenciado las prácticas turísticas de las prácticas cotidianas. Así, Ralph (1976) las clasifica de acuerdo con el comportamiento de los locales, habitantes de un lugar determinado, en oposición a los extraños, que llegan de fuera y no tienen actividades cotidianas. Estas distinciones entre prácticas rutinarias y no rutinarias asociadas a lugares cotidianos y no cotidianos permite conceptualizar los espaciostiempos del turismo y los modos de residencia (Figura 2).

\section{Figura 2}

El espacio-tiempo del turismo y de los tiempos libres

\section{EL ESPACIO-TIEMPO DEL TURISMO Y DE LOS TIEMPOS LIBRES}

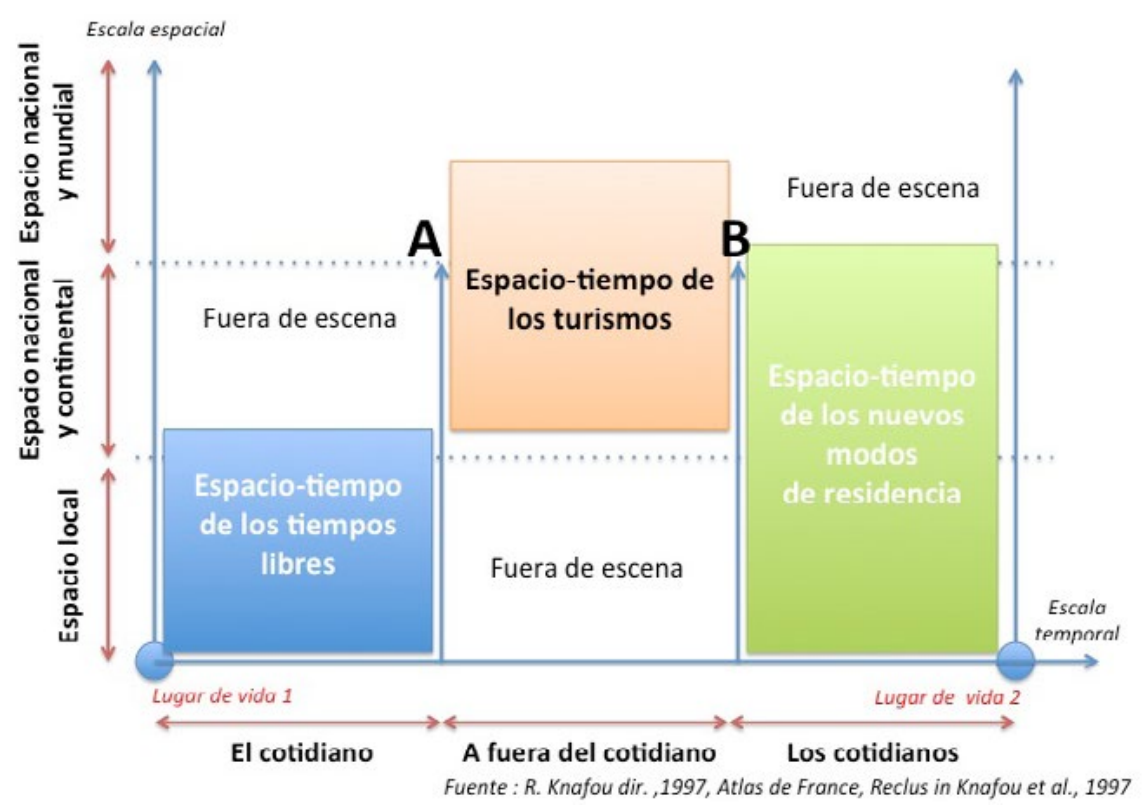

Fuente: Knafou, R. Atlas de France. París: La Documentation Française, 1997.

Las turistas construyen su proyecto turístico de acuerdo a dos preguntas fundamentales estrechamente ligadas: una favorece al destino, el lugar donde desean poner en práctica su proyecto; la otra a la práctica ${ }^{33}$. El proyecto turístico es lo que se propone hacer en algún momento, y forma parte de una gestión general que incluye la preparación y la imaginación del viaje $\mathrm{e}^{34}$ : el proyecto preside a las prácticas y anticipa su progreso. Sin embargo, es posible que el individuo cambie de idea para

33 Violier, "Tourisme et médias", 159-170.

34 Equipe MIT. Tourismes 1. Lieux communs (París: Belin, 2002). 
que sus prácticas reales no correspondan con el proyecto original. Así, la intención de recreación se realiza a través de la elaboración de un proyecto y la elección de un destino, para luego ejecutar el proyecto a través de la práctica turística. Aquí, la alteridad se convierte en el medio por el cual se va a implementar el proyecto turístico a las prácticas turísticas $^{35}$. Esta lectura geográfica del turismo centrado en el turista está relacionada también con el espacio.

\section{El TRASPAÍS: ALGUNAS APORTACIONES TEÓRICAS}

Aunque la reflexión sobre los márgenes, periferias y traspaíses en geografía no es nueva, entre 1997 y 2016 se detecta una ausencia de reflexión sobre esta temática. Todas las definiciones y reflexiones siguientes se alimentan en el corpus teórico sobre el cual me basaré para definir la región estudiada como traspaís Cancún-Riviera Maya. En francés, el diccionario "le Petit Robert" en $1959^{36}$ define el traspaís como "una región ubicada atrás de una región costera" en un primer sentido, y en

35 L. Li, "Pratiques tourstiques".

36 En el plan teórico, el término de traspaís (hinterland en inglés y alemán y arrière-pays en francés) proviene de la geografía económica de los transportes o más exactamente de la geografía portuaria. Lo atribuimos a Chisholm (1889), un geógrafo norteamericano en lengua inglesa. Según este autor, un traspaís designa el área de atracción y de vínculos de un puerto (generalmente marítimo, excepcionalmente fluvial o lagunar), o el espacio continental de un puerto vinculado al almacenamiento de mercancías. Se trata fundamentalmente de un concepto de geografía humana y no debe ser considerada como una denominación inmóvil. Cualquier espacio ubicado atrás de una zona litoral no constituye necesariamente un traspaís. Los autores separan un traspaís de un país de adelante (o foreland en inglés) constituido por los destinos vinculados a este puerto en el mundo. A veces, un mismo binterland puede ser vinculado por diferentes puertos en competencia en el seno de un mismo espacio y compartiendo el almacenamiento de las mercancías como lo describieron algunos geógrafos del transporte (Jean Charlier, "Contribution méthodologique à l'étude des arrière-pays portuaires" (tesis de doctorado en Geografía, Université catholique de Louvain, 1981); Jean Charlier, "L'arrière-pays national du port du Havre", Espace géographique, 194 (1990), 325-334); Alain Vigarie, Ports de commerce et vie littorale (París: Hachette, 1979); Alain Vigarie, "L'évolution de la notion d'arrière-pays en économie portuaire", Transports No. 428 (2004): 372-387). Por otra parte, después de mencionar el primer sentido de un hinterland en geografía portuaria en el Diccionario de la geografía, Bernard afirma que se trata, por extensión, de cualquier espacio que ofrezca los recursos a un nodo, y considera este concepto describiendo todas las situaciones donde las relaciones se establecen entre dos espacios distintos y complementarios: “(...) entre otros el espacio polarizado por un lugar central o el área de influencia de un establecimiento particular localizado en este lugar central" (A. Bernard, "Hinterland”, en Dictionnaire de la géographie, eds. Jacques Levy y Michel Lussault (París: Belin, 2003), 497. 
un segundo sentido como "un área de atracción o de vínculo comercial de un puerto".

Si bien algunos geógrafos intentaron delimitar este espacio, muchas veces complicado de definir o susceptible a variación, los límites administrativos no permiten darnos cuenta de la realidad de este espacio. Así, Brunet, Ferras y Théry en Les mots de la Géographie afirma que un traspaís posee "una localización ideológica y geográfica designando un complemento espacial en forma de hacer valer, trasero en relación a adelante, $y$ además siendo alto en comparación a abajo, de una periferia rural en relación a un centro generalmente urbano"37. Cabe mencionar que el número 6 de la Revista Montagnes Méditerranéennes (1997) y su dossier está consagrado a la noción de traspaís, y a las dinámicas y retos de márgenes y periferias en montañas mediterráneas. Hervé Gumuchian ${ }^{38}$ finaliza la introducción con una fórmula muy interesante: «los márgenes reservan siempre sorpresas». El traspaís aparece entonces como un espacio fuertemente semantizado.

Sin embargo, Giraut desconoce la oposición entre litoral y traspaís en lugar de una oposición entre país y traspaís ${ }^{39}$, este país siendo unas montañas turísticas, un valle industrial, o una zona urbana; un espacio desarrollado que ocupa una posición central y no necesariamente litoral. Otros autores ilustran esta definición con ejemplos localizados en el Sur de Francia: Roux afirma que el valle de la Haute-Bléone es un traspaís en construcción ${ }^{40}$, y Fesnau demuestra que el Queyras no es del todo un país y resulta en un traspaís del Guillestrois ${ }^{41}$.

37 Roger Brunet, Robert Ferras y Henry Thery, Les mots de la géographie: dictionnaire critique (Montpellier: Reclus La documentation Française, 1992), 470.

38 Henri Gumuchian, "A propos de quelques notions: marges, périphéries et arrière-pays", Montagnes Méditerranéennes $\mathrm{N}^{\circ} 6$ (1997): 9-11.

39 Frédéric Giraut, "Pays et arrière-pays. Quelques hypothèses sur la nature et les fonctions contemporaines des arrière-pays de montagnes méditerranéennes", Montagnes Méditerranéennes ํ 6 (1997): $15-17$.

40 Emmanuel Roux, "La vallée de la Haute-Bléone, arrière-pays d'un pays dignois en construction?", Montagnes Méditerranéennes $\mathrm{N}^{\circ} 6$ (1997): 77-82.

41 incent Fesnau, "Le Queyras: entre pays et arrière-pays”, Montagnes Méditerranéennes № 6 (1997): $91-95$. 
Suchet y Anton-Clavé ${ }^{42}$ recuerdan que esta misma temática había sido abordada en 1998, durante las jornadas sobre "traspaíses turísticos en el mundo mediterráneo"43, organizadas en la Universidad de Avignon por la Comisión de Geografía del turismo y de los ocios del Comité Nacional Francés de Geografía (CNFG). Knafou estimaba que era conveniente cuestionar la pertinencia y la utilidad de este concepto de traspaís desde la geografía y particularmente desde la geografía de turismo ${ }^{44}$, mismo concepto está implícito en los trabajos de algunos geógrafos anglosajones como Weaver ${ }^{45}$. Dieciséis años más tarde, en 2014, la Comisión de Geografía de turismo y de los ocios del CNFG se reunió en la Universidad de Bretaña Occidental en Quimper para discutir en torno al tema "Turismo, margen y periferia"46. Tres propuestas utilizaban explícitamente el término "traspaís" en el título de su comunicación. La contribución de André Suchet y Anton Clavé hacía una pregunta iconoclasta: ¿necesitamos el concepto de traspáis en geografía del turismo? La contribución oral fue ilustrada con diversos ejemplos. S. Christofle y C. Hélion se interesaron en el fracaso de la turistificación de los márgenes de un alto lugar turístico, la Côte d'azur. Su objetivo estaba en el cuestionamiento del bajo desarrollo turístico caracterizando esta parte de los Alpes, una de las menos valorizadas ${ }^{47}$. Finalmente, la última propuesta sobre el traspaís maya en Cancún será nuestro centro de interés en esta reflexión ${ }^{48}$.

42 A. Suchet y Anton-Clave, S, "A-t-on vraiment besoin du concept d'arrière-pays en géographie du tourisme?", en Colloque Tourisme, marge et périphérie, editado por las jornadas No 41 de la comisión de geografía del turismo y de ocío, Quimper, 2014.

43 Traducción de «Arrière-pays touristiques dans le monde méditerranéen».

44 Las actas del Congreso fueron publicadas en un número de la revista Études vauclusiennes reuniendo una decena de textos (Knafou, Rémy 1998).

45 David Weaver. "A broad context model of destination development scenarios", Tourism Management $\mathrm{N}^{\circ} 21$ (2000): 217-224.

46 Traducción de "Tourisme, marge et périphérie»

47 Christophe Helion y Sylvie Christofle, "Moyen et haut-pays azuréens: l'échec d une touristification des marges d'un haut-lieu du tourisme mondial, en colloque", en Tourisme, marge et périphérie, editado por 41ème journées de la commission de géographie du tourisme et des loisirs (Quimper: s/e, 2014).

48 Samuel Jouault, Ana García de Fuentes y Marcela Jiménez, "L’arrière-pays touristique de Cancún Riviera Maya", en Tourisme, marges et périphéries, eds. Nicolas Bernard, Caroline. Blondy y Philippe Duhamel. (Rennes: Presses Universitaires de Rennes, 2017), 233-252. 


\section{La región estudiada: la Península de Yucatán}

La península de Yucatán en su extensión máxima, conformada por los estados de Yucatán, Campeche y Quintana Roo, ocupa una porción de tierra de aproximadamente $145,000 \mathrm{~km}^{2}$. Desde el punto de vista geológico y fisiográfico la Península es una enorme planicie formada por rocas calizas, que se prolonga sobre Belize y el Petén guatemalteco. Su relieve kárstico está formado por ondulaciones, dolinas y cenotes ${ }^{49} \mathrm{y}$ solo destaca la "Sierrita de Ticul" cuya elevación máxima no alcanza los $400 \mathrm{msnm}$.

La península también es una zona de altas complejidades ecológicas derivadas de la fragmentación de los paisajes, ocasionada a su vez por la expansión agropecuaria y la deforestación. Entre los factores que favorecen la diversidad de ecosistemas en la península se encuentra su localización entre la ecorregión neotropical, con unidades climáticas tales como cálido subhúmedo en una porción superior al $80 \%$ en toda la extensión del territorio, con un menor porcentaje de cálido húmedo en la Isla de Cozumel y la parte suroeste de Campeche en colindancia con Tabasco (incluyendo la reserva de los pantanos de Centla), y donde únicamente en los litorales de Yucatán se concentran unidades climáticas semi secas y secas en la parte norte (costa occidental). Esto propicia en la península una mayor subsistencia y diversidad de especies de fauna y flora, esta última con predominante vegetación secundaria y elementos de disturbio que alteran o modifican la estructura de la composición florística (de forma natural o antrópica). Algunos ecosistemas representativos son: las selvas bajas, medianas y altas, principalmente distribuidas en la región noroeste del estado de Quintana Roo y en la parte sureste de Campeche, especialmente en la reserva de la biosfera de Calakmul. De igual manera, los litorales de la plataforma peninsular tienen presencia de humedales en una gran porción de su extensión,

49 Cenote deriva de la palabra maya "d'zonot”, que significa caverna con depósito de agua. Se trata de cavidades originalmente subterráneas, circulares y de amplitud variable, que se forman a partir de la disolución y carbonatación de estratos calcáreos del subsuelo, quedando la coraza calcárea exterior a manera de bóveda, que con el tiempo puede derrumbarse parcial o totalmente, dejando estas oquedades expuestas a cielo abierto. 
abrigada por vegetación hidrófila, manglares y petenes que caracterizan el paisaje costero y albergan gran cantidad de biodiversidad ${ }^{50}$.

Desde un punto de vista cultural, es imprescindible mencionar la presencia de la etnia maya que permanece viva en los tres estados -particularmente en el medio rural-, y es ostensible a través de rasgos como su composición económica y producción primaria, su particular estructura familiar en el solar y su vivienda tradicional. Es necesario reconocer el papel vital de la cultura maya en la construcción de la identidad regional, al ser la península de Yucatán una región cultural unida a un paisaje natural. Estas características confieren al territorio una identidad claramente diferenciada de la del resto del país ${ }^{51}$. Un factor relevante sobre esta diversidad cultural emanada de las localidades rurales distribuidas en el territorio peninsular, de las cuales un estimado de $25 \%$ vive en ellas y un $75 \%$ de la población vive en localidades urbanas ${ }^{52}$ como se indica en la Tabla 2 que se presenta a continuación.

Tabla 2

Población total y maya hablantes en la Península de Yucatán

\begin{tabular}{|l|c|c|c|}
\hline \multicolumn{1}{|c|}{ Estado } & Población total (2015) & $\begin{array}{c}\text { Hablante indígena } \\
\text { (estimación 2015) }\end{array}$ & Porcentaje (\%) \\
\hline Yucatán & $2,097,175$ & 537,516 & $26 \%$ \\
\hline Campeche & $1,501,562$ & 255,266 & $17 \%$ \\
\hline Quintana Roo & 899,931 & 107,992 & $12 \%$ \\
\hline Total & $4,498,668$ & 900,774 & $20 \%$ \\
\hline
\end{tabular}

Fuente: elaboración propia con datos de inegi. Encuesta Intercensal 2015, Ciudad de México: inegi 2015. http://www. beta.inegi.org.mx/proyectos/enchogares/especiales/intercensal/(consultada el 15 febrero 2016).

50 Instituto Nacional de Estadística y Geografía (inegi), Anuario estadístico de los Estados Unidos Mexicanos 2014, Ciudad de México: inegi, 2014.

http://internet.contenidos.inegi.org.mx/contenidos/productos/prod_serv/contenidos/espanol/ bvinegi/productos/anuario_14/702825066482.pdf (consultado el 15 febrero 2016);

51 Ana García de Fuentes, Samuel Jouault, y David Romero, Atlas de turismo alternativo de la Península de Yucatán (Mérida: Universidad Autónoma de Yucatán y Centro de Investigaciones y Estudios Avanzados (cinvestav)-Unidad Mérida, 2015).

52 Instituto Nacional de Estadística y Geografía (INEGI). Censo Nacional de Población y Vivienda : INEGI, 2010 http://www.inegi.org.mx > Estadistica 
En este contexto, es preciso indicar que en la península no solo es abundante la diversidad biológica, sino que permea un enfoque de bioculturalidad que mantiene latente la historia y cultura de los pueblos indígenas y su relación con el entorno natural. Así, son plenamente estos rasgos histórico-culturales de los pueblos mayas los que les otorgan a los paisajes un significado y simbolismo, y los reconstruyen con el devenir del tiempo y de acuerdo con sus rasgos ideológicos, así como sus necesidades ${ }^{53}$.

\subsection{La TURISTIFICACIÓN DE LOS ESPACIOS RURALES EN YUCATÁN}

La turistificación de los espacios naturales y rurales no es uniforme en la península, y existen similitudes y diferencias en el mecanismo de puesta en valor turístico de un territorio. El tema de investigación es necesario, sobre todo en una época en la que se cree que solamente a través de infraestructuras y equipamientos, un espacio puede volverse turístico. En este contexto, los miembros de las sociedades locales poseen un papel clave en el despliegue del desarrollo turístico.

La llegada de los turistas a un lugar o destino implica una co-presencia entre los individuos foráneos y temporales de ese destino y los habitantes permanentes, miembros de la sociedad local. La co-presencia de turistas y sociedad local en los mismos espacios es provechosa, pues el turismo no puede desarrollarse sin el acuerdo de la sociedad local. Como lo anunciaba el geógrafo francés Remy $\mathrm{Knafou}^{54}$, existe un contrato tácito entre los turistas y las sociedades locales, aunque la turistificación del espacio puede crear problemas y tensiones. En la península de Yucatán podemos caracterizar esta turistificación en cinco etapas, que describiremos de la manera siguiente (Tabla 3):

53 Ana García de Fuentes, Samuel Jouault, y David Romero, Atlas de turismo; Samuel Jouault, Ana García de Fuentes y Marcela Jiménez, "L’arrière-pays touristique”, 233-252.

54 R. Knafou "L'invention du lieu touristique: la passation d'un contrat et le surgissement simultané d'un nouveau territoire", Revue de géographie alpine, 4 (1991): 11-19. 


\section{Tabla 3}

Etapas de la turistificación de la Península de Yucatán

\begin{tabular}{|l|l|}
\hline \multicolumn{1}{|c|}{ Etapas } & \multicolumn{1}{c|}{ Descripción } \\
\hline $\begin{array}{l}\text { Etapa 1: } \\
\text { El prototurismo, el } \\
\text { redescubrimiento } \\
\text { del patrimonio } \\
\text { edificado }\end{array}$ & $\begin{array}{l}\text { El turismo en la Península de Yucatán tiene su origen en los descubrimientos arqueo- } \\
\text { lógicos de finales del siglo XIX y principios del XX y en el papel que desempeñaron } \\
\text { exploradores como John Stephens, diplomático americano, y Frederick Catherwood, } \\
\text { quienes durante varios años de la década de 1840 recorrieron el área maya de la } \\
\text { península y la documentaron en su libro Incidentes de viajes en Yucatán (1843). }\end{array}$ \\
\hline $\begin{array}{l}\text { Etapa 2: } \\
\text { El despegue y el } \\
\text { comienzo del tu- } \\
\text { rismo en el Caribe } \\
\text { mexicano }\end{array}$ & $\begin{array}{l}\text { Con la comunicación terrestre entre la península y el centro del país (el ferrocarril en } \\
\text { 1949 y la carretera en 1959), se inicia un turismo nacional e internacional incipiente } \\
\text { en la región, motivado principalmente por la arqueología. Destaca el papel visionario } \\
\text { del empresario Fernando Barbachano Peón que inicia vuelos comerciales, agencias de } \\
\text { viajes y hotelería en el estado de Yucatán a partir de los años cuarenta. }\end{array}$ \\
\hline $\begin{array}{l}\text { Etapa 3: } \\
\text { El éxito turístico de } \\
\text { Cancún }\end{array}$ & $\begin{array}{l}\text { En la década de 1970 la organización económica y territorial de la península se vuelca } \\
\text { hacia un nuevo polo rector: el Centro turístico Integralmente Planeado Cancún, en la } \\
\text { costa de Quintana Roo. Gracias al éxito de este proyecto turístico, Quintana Roo se } \\
\text { ha mantenido entre los estados con las tasas de crecimiento poblacional más altas del } \\
\text { país por varias décadas y Cancún se ha convertido en un centro urbano de relevancia } \\
\text { regional. Este desarrollo constituye un polo de atracción para la población de las } \\
\text { localidades de la región, cuyos habitantes se emplean convencionalmente en servicios } \\
\text { vinculados al turismo y la construcción. }\end{array}$ \\
\hline $\begin{array}{l}\text { La diferenciación en términos de intensidad entre la Riviera Maya y el litoral yucate- } \\
\text { co, la Costa Maya (sur de Quintana Roo), Isla Mujeres y Holbox es clara, por lo que } \\
\text { proponemos diferentes lecturas: }\end{array}$
\end{tabular}

a) Riviera Maya. Después de la creación de Cancún, el desarrollo turístico se intensificó y se expandió en la década de 1990 a lugares como Cozumel, Playa del Carmen y Tulum, entre otros. Comienza la expansión de los proyectos turísticos sobre el litoral de Quintana Roo.

b) El Litoral yucateco. En Yucatán, el turismo asociado a la costa ha evolucionado en tres vertientes: 1) el desarrollo de casas de segunda residencia de familias que se trasladan durante los períodos vacacionales a las playas; 2 ) el desarrollo de la hotelería en los años setenta; y 3 ) el inicio, a partir de 2004, de la modalidad de turismo alternativo, como resultado de las políticas estatales, federales e internacionales relaciona-

Etapa 4:

Expansión de los corredores turísticos litorales das con la importancia de los humedales costeros y la necesidad de conservarlos. c)La Costa Maya (turismo de cruceros). Es parte de un proyecto amplio que intenta colocar al sur de Quintana Roo en un horizonte turístico de mayor envergadura. El propósito es integrarlo tanto al principal corredor turístico del país que es el Caribe mexicano como a la región turística internacional denominada Mundo Maya, y consolidarlo como una plaza de cruceros de importancia en el Caribe.

d) Isla Mujeres. Las propias características de la isla -limitado tamaño, presencia de la base naval, entre otras-imponen un límite al desarrollo hotelero y confieren a la isla una personalidad propia más vinculada al contacto con la naturaleza, a través de su oferta de buceo con esnórquel, visitas al Parque Nacional Isla Contoy y avistamiento del tiburón ballena. Por otra parte, por su cercanía a Cancún, funciona a manera de bisagra entre esta región de turismo masivo y las ofertas más limitadas de ecoturismo y turismo de aventura en altamar del norte de Quintana Roo.

e) La flecha de barrera de Holbox. Ha creado una oferta de pequeños hoteles que mantienen características similares a los de Isla Mujeres, y basan su turismo en playas menos concurridas, y en el avistamiento entre mayo y septiembre del tiburón ballena (especie bandera). 


\begin{tabular}{|l|l|}
\hline \multicolumn{1}{|c|}{ Etapas } & \multicolumn{1}{c|}{ Descripción } \\
\hline & $\begin{array}{l}\text { Paralelamente a la gestación en 1988 del plan regional llamado Programa Mundo } \\
\text { Maya } 55 \text {, fueron decretadas diferentes Áreas Naturales Protegidas como el caso de la } \\
\text { Reserva de la Biosfera Calakmul en 1989. El Programa Mundo Maya, cuyo compro- } \\
\text { miso fue el fortalecimiento y promoción de un turismo «más sustentable», a través de }\end{array}$ \\
$\begin{array}{l}\text { Etapa 5: } \\
\text { Auge y expansión } \\
\text { del turismo } \\
\text { alternativo en la } \\
\text { Península de } \\
\text { Yucatínas de crear vías de comunicación en el interior, rescatar y ofertar sitios ar- } \\
\text { queológicos y promover la construcción de infraestructura turística en comunidades } \\
\text { rurales del interior, tales como cabañas, restaurantes o venta de artesanías (Daltabuit } \\
\text { et al., 2000), fue en realidad un proyecto de promoción de esta región turística hacia } \\
\text { el viejo continente. Pero en ese lapso aparecen también las primeras empresas socia- } \\
\text { les que ofertan actividades de turismo alternativo en tierras del interior. En la década } \\
\text { de 2000, la iniciativa de la Organización Mundial del Turismo (OMT) de promoción } \\
\text { del turismo alternativo permea los esquemas de planeación turística en México. }\end{array}$ \\
\hline
\end{tabular}

Fuente: elaboración propia basado en A. García de Fuentes, S. Jouault, y D. Romero, Atlas de turismo alternativo de la Península de Yucatán (Mérida: Universidad Autónoma de Yucatán y Centro de Investigaciones y Estudios Avanzados (CINVEstav)-Unidad Mérida, 2015).

El traspaís del corredor Cancún-Riviera Maya ${ }^{56}$ es una región en la que las comunidades rurales del interior han elegido desarrollar actividades turísticas a partir de las posibilidades ofrecidas por su localización y características físico-geográficas y socioculturales. Dichos rasgos dan como resultado una oferta turística alternativa y complementaria a la modalidad litoral de masas. Este traspaís brinda al turista la posibilidad de diversificar sus prácticas turísticas hacia la cultura y la naturaleza a través del descubrimiento del "mundo maya profundo" y de la "exuberante selva tropical".

\subsection{Los traspaíses turísticos de la Península de Yucatán, ¿NUEVOS LÍMITES CARIBEÑOS?}

El traspaís de Cancún-Riviera Maya se conformó a partir de los hoteles all-inclusive ${ }^{57}$ del litoral Cancún-Riviera Maya, los cuales se asemejaban, según autores y los propios hoteleros, a cruceros en tierra, pirámides construidas por los Mayas en el siglo XX o templos modernos del

55 El programa Mundo Maya surge a iniciativa de la Comunidad Económica Europea, la Organización Mundial del Turismo (Омт) y la National Geographic Society, en colaboración con los gobiernos de México y Centroamérica (Guatemala, Belice, El Salvador y Honduras).

56 La región turística más importante de México, y una de las principales del Caribe y de América Latina.

57 Nombre coloquial de los hoteles donde todos los alimentos y bebidas están servidas sin ningún límite. 
consumo $^{58}$. Los otros dos traspaíses se conforman como hinterland de los puertos de Progreso, ubicado en el litoral norte de la Península de Yucatán, o del puerto del megaproyecto Costa Maya (Figura 3). En estos traspaíses, las prácticas de descubrimiento y juego son complementarias a la práctica principal encontrada en los cruceros y litorales: el descanso y cuidado del cuerpo. La exuberante selva maya de este traspaís tiene mucho que ofrecer a los turistas albergados en su gran mayoría en las infraestructuras del litoral quintanarroense, como se ha demostrado en el Atlas de turismo alternativo de la Península de Yucatán (García de Fuentes et. al, 2015) (Tabla 4). Los cruceros que atracan temprano por la mañana y levantan el ancla antes del atardecer permiten a los más aventureros -o, mejor dicho, a los turistas que cuentan con recursos económicos asociados a una curiosidad-, descubrir otros destinos además de los puertos de atraque. En Yucatán, los destinos son en su mayoría propuestos por las navieras, agencias a bordo o vinculadas a las compañías de crucero, las que ofrecen el descubrimiento de sitios arqueológicos prehispánicos (Tabla 5, Figura 6).

\section{Tabla 4}

Prácticas turísticas en los traspaíses de la Península de Yucatán

\begin{tabular}{|l|l|l|l|}
\hline Tipo de práctica & \multicolumn{1}{|c|}{ Oferta } & Recursos predominantes & $\begin{array}{l}\text { Actividades predomi- } \\
\text { nantes }\end{array}$ \\
\hline Descubrimiento & $\begin{array}{l}\text { Recorrido de } \\
\text { naturaleza en } \\
\text { el interior }\end{array}$ & $\begin{array}{l}\text { Vegetación de selva, aves, } \\
\text { monos araña o aulladores, } \\
\text { lagunas, cuevas y vestigios } \\
\text { arqueológicos }\end{array}$ & $\begin{array}{l}\text { Recorridos por sende- } \\
\text { ros interpretativos y } \\
\text { avistamiento de fauna, } \\
\text { ciclismo, tirolesa, ra- } \\
\text { ppel, kayakismo y nado } \\
\text { en lagunas y cenotes }\end{array}$ \\
\hline Juego & Visita a cenote & Cenotes y vegetación de selva & $\begin{array}{l}\text { Nado en cenotes, ciclis- } \\
\text { mo, kayakismo, tirolesa } \\
\text { y rappel }\end{array}$ \\
\hline Descubrimiento & Turismo rural & $\begin{array}{l}\text { Recursos gastronómicos y ar- } \\
\text { tesanales, vegetación de selva, } \\
\text { fauna local, recursos herbola- } \\
\text { rios y ceremonias mayas }\end{array}$ & $\begin{array}{l}\text { Talleres artesanales, de } \\
\text { medicina tradicional y } \\
\text { gastronómicos }\end{array}$ \\
\hline
\end{tabular}

Fuente: elaboración propia. Adaptado de A. García de Fuentes, S. Jouault, y D. Romero, Atlas de turismo alternativo de la Península de Yucatán (Mérida: Universidad Autónoma de Yucatán y Centro de Investigaciones y Estudios Avanzados (cinvestav)-Unidad Mérida, 2015).

58 Lucie Dufresne. Les mayas et Cancún. (Montréal: Presses de la Université de Montréal, 1999). 


\section{Tabla 5}

Destinos ofertados por las compañías de crucero que atracan en Progreso (Yucatán) y

Majahual (Quintana Roo)59

\begin{tabular}{|l|l|l|}
\hline $\begin{array}{c}\text { Destinos en la Penín- } \\
\text { sula de Yucatán }\end{array}$ & \multicolumn{1}{|c|}{ Compañía } & \multicolumn{1}{c|}{ Destinos } \\
\hline \multirow{5}{*}{ Progreso } & P\&O & $\begin{array}{l}\text { Chichén Itzá, Mérida, Dzibilchaltún, Ux- } \\
\text { mal, Hacienda Ochil, Xcambó, Dzemul, }\end{array}$ \\
\cline { 2 - 3 } & Royal & No disponible \\
\cline { 2 - 3 } & Carnival & No disponible \\
\cline { 2 - 3 } & Azamara & Dzibilchaltún, Malecón, el Faro \\
\hline \multirow{5}{*}{ Majahual } & Princess Cruises & $\begin{array}{l}\text { Kohunlich, Chacchoben, Dzibanché, Uvero } \\
\text { beach club, snorkel, Lost Mayan Kingdom, } \\
\text { Mayan Cultural Experience }\end{array}$ \\
\cline { 2 - 3 } & Azamara & Chacchoben \\
\cline { 2 - 3 } & Royal & Chacchoben \\
\cline { 2 - 3 } & Carnival & Chacchoben \\
\cline { 2 - 3 } & P\&O & Chacchoben \\
\hline
\end{tabular}

Fuente: elaboración propia basado en trabajo de investigación.

59 Excluimos el puerto de Cozumel de esta tabla porque consideramos que son cruceros en tierra, los famosos hoteles all-inclusive quienes fungen como cruceros en el caso del traspaís de Cancún-Riviera Maya. 


\section{Figura 3}

Los traspaíses de la Península de Yucatán

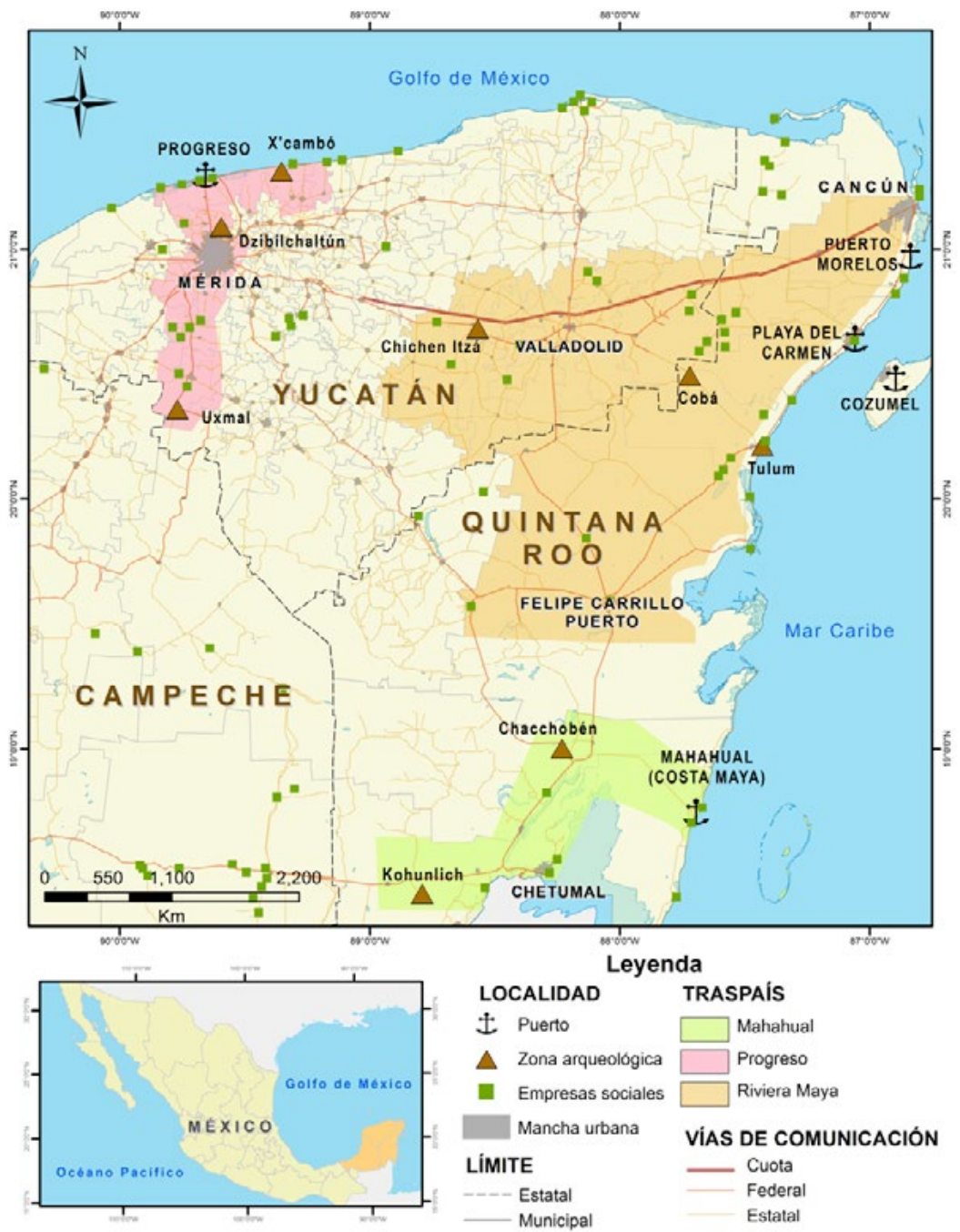

Fuente: elaboración propia. Realización: Alejandro Montañez Giustinianovic.

La empresa Princess Cruise, que atraca en Majahual, pone énfasis en el carácter maya del destino, así como en la región interior contigua que puede considerarse un área de influencia (traspaís) en la que se desarrolla

74 una oferta de turismo de naturaleza y cultural: Kohunlich, Chacchoben, Dzibanché y la "experiencia cultural maya", como alternativa al turismo de sol y playa que es la actividad principal del litoral (Figura 6). Las acti- 
vidades de descubrimiento propuestas al crucerista son parte del tejido del traspaís de la Costa Maya. Este tejido se realiza a partir de líneas, como los ejes carreteros que vinculan el puerto de Majahual con estos lugares, que serían los nodos de los ejes carreteros.

\section{Figura 6}

Lo maya, atractivo turístico en Majahual según Princess Cruises

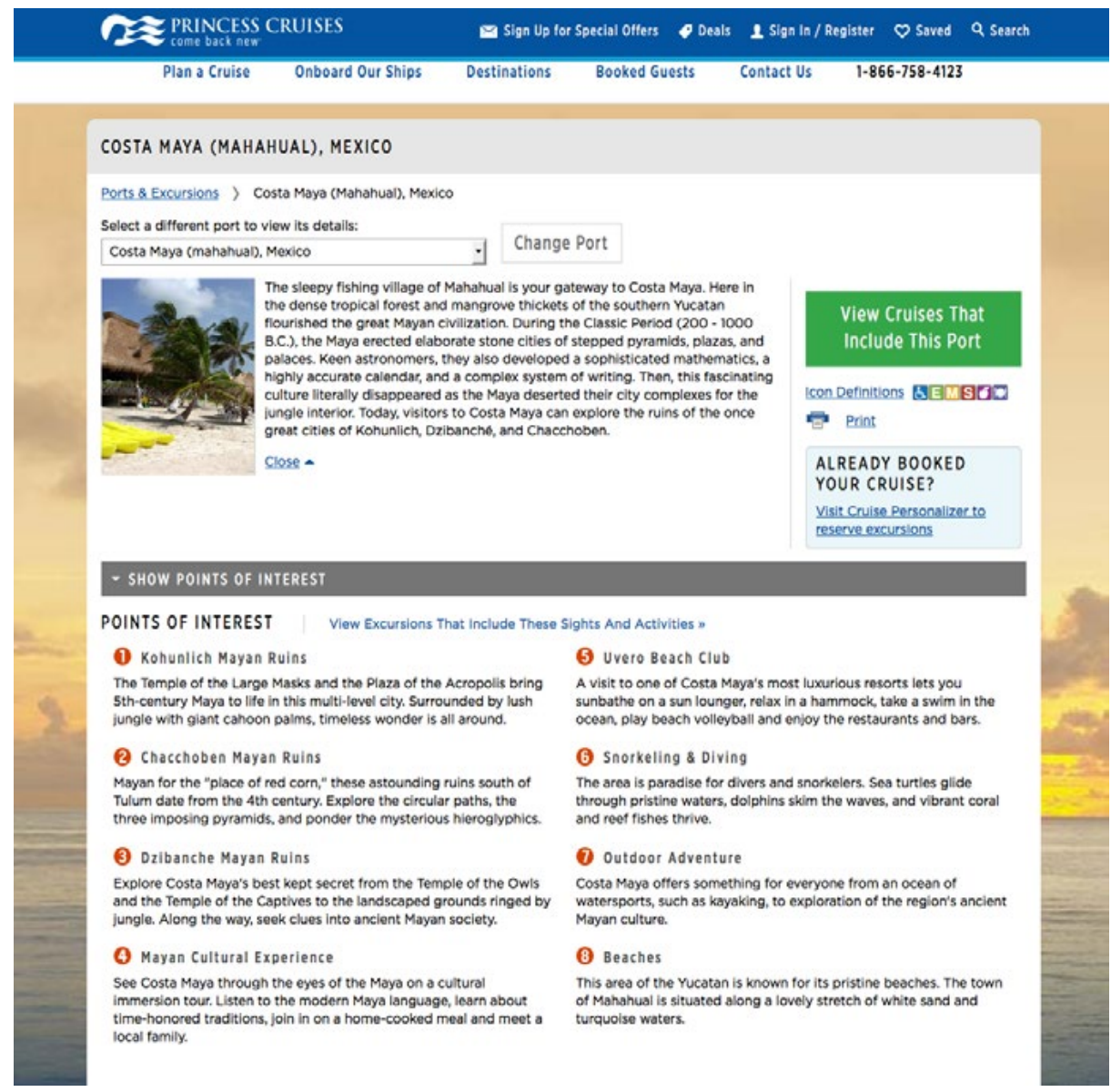

Fuente: Portal de Princess Cruises. http://www.princess.com (consultado el 15 de diciembre de 2017).

El traspaís representa la diversificación de la oferta turística clásica: los mismos turistas que visitan y se hospedan en el corredor litoral son quienes constituyen el mercado principal para las empresas del traspaís. Pero el traspaís representa una nueva territorialidad caribeña a causa del vínculo entre el turista y nuevos destinos. 


\section{Conclusión}

La aproximación renovada del turismo permite analizar el fenómeno de manera cualitativa, examinar las movilidades y prácticas turísticas, revisitar el turismo y el tiempo libre desde una perspectiva geográfica. A una geografía turística clásica basada en la localización de los lugares turísticos la sucede una aproximación geográfica del turismo, que aporta su contribución no solamente a la reflexión sobre el turismo en sí, sino también a sus implicaciones espaciales, tales como las relaciones entre el turismo y la producción de espacios y nuevas territorialidades.

Esta aproximación geográfica del turismo cuestiona los límites del Caribe Continental: estos no se detienen en aspectos geodinámicos, tales como la amplitud más alta de las mareas, los límites administrativos de los pueblos, puertos o municipios costeros. Sin oferta no hay demanda y vice-versa. Por ello no es posible concebir estas prácticas y movilidades turísticas sin tomar en cuenta los destinos existentes (por ejemplo, zonas arqueológicas o lagunas) o inventados para atraer a estos potenciales turistas.

Sin embargo, ¿qué aporta esta lectura turística del espacio? Primero, a través del turismo puede explorarse el dinamismo del espacio. Por ejemplo, en 2006 y con la esperanza de vincular el lugar a Costa Maya, nace, subsidiado por diferentes órganos gubernamentales, el parque Ecoturístico Uchben Kah en el ejido Pedro Antonio Santos -al norte de la laguna de Bacalar, Quintana Roo-. Si bien este lugar apareció en los mapas, la baja frecuentación del Puerto de Majahual -debido al Huracán Dean en 2007 y a las alertas internacionales con la propagación del virus H1N1 en 2009-, asociada a una mala gestión del parque y a la poca cooperación por parte de las navieras ocasionó que lo borraran rápidamente. Segundo, el turismo tiene la capacidad de transformar los espacios en una inversión espacial, pensada para un período de tiempo largo. Los litorales no son turísticos por naturaleza, lo son porque unas sociedades confieren un valor particular, estético y "recreativo" a los paisajes y las prácticas desarrolladas en ese litoral. Esta capacidad del turismo a transformar los espacios no es manifiesta solamente en los litorales: el cenote de Yokdzonot cerca de Chichen Itzá era antes 
de 2006 un basurero, hoy día recibe 35,000 turistas por año. Tercero, el turismo puede ser un prisma de observación de las sociedades locales: estas últimas desarrollan estrategias para adaptarse y apropiarse el hecho turístico, y al mismo tiempo se vuelven turistas y se reapropian estos espacios consumidos por los de afuera, sean turistas internacionales o nacionales. En este triple sentido, la aproximación geográfica del turismo permite definir y explorar nuevos límites al Caribe Continental.

\section{Bibliografía}

Ashby, Soyini, Cruse, Romain y Rhiney Kevon (eds.). La Caraïbe est une histoire, quelle que soit la langue. Caribbean Atlas, 2013. http:// www.caribbean-atlas.com/fr/thematiques/qu-est-ce-que-la- caraibe/la-caraibe-est-une-histoire-quelle-que-soit-la-langue.html

Bégot, Monique y Pascal Buleon, Una Cuenca en el Mundo en Atlas Caribe. Normandie: Universidad de Caen, 2017. http://atlas-caraibe.certic.unicaen.fr/es/theme-10.html

Bernard, Alain., "Hinterland". En Dictionnaire de la géographie, editado por J. Levy y M. Lussault, París: Belin, 2003, 497.

Brunet, Roger, Robert Ferras y Hervé Thery, Les mots de la géographie: dictionnaire critique. Montpellier: Reclus La documentation Française, 1992.

Charlier, Jean, “Contribution méthodologique à l'étude des arrière-pays portuaires". Tesis de doctorado en Geografía, Université catholique de Louvain, 1981.

Charlier, Jean, "L'arrière-pays national du port du Havre". Espace géographique 194 (1990): 325-334.

Chisholm, George, Handbook of commercial geography. London: Longman, Green \& Co., 1889.

Cruse, Romain en Cruse Romain y Rhiney Kevon (eds.), Introduction à la Caraibe perçue. Schoelcher Cédex (France): Caribbean Atlas, 2013 http://www.caribbean-atlas.com/fr/thematiques/qu-estce-que-la-caraibe/introduction-a-la-caraibe-percue.html.

Cuvelier, Pascal. Anciennes et nouvelles formes de tourisme: une approche socio-économique. París: L’Hammatan, 1998. 
DATATUR. Compendio Estadístico del Turismo 2016. Ciudad de México: Secretaría de Turismo (SECTUR), 2016. http://www.datatur. sectur.gob.mx/SitePages/CompendioEstadistico.aspx

Dehoorne, Olivier, Christelle Murat y Nathalie Petit-Charles. "Le tourisme de croisière dans l'espace caribéen: évolutions récentes et enjeux de développement". Études caribéennes 13-14 (2009). http:/ /etudescaribeennes.revues.org/3843;DOI: 10.4000/etudescaribeennes.3843

Dehoorne, Olivier y Nathalie Petit-Charles. "Tourisme de croisière et industrie de la croisière". Études caribéennes 18 (2011). http:/ / journals.openedition.org/etudescaribeennes/ 5623

Dufresne, Lucie. Les mayas et Cancún. Montréal: Presses de la Université de Montréal, 1999.

EQUipe MIT. La mise en tourisme des lieux: un outil de diagnostic.

París: Belin, 2000.

EQUiPe MIT. Tourismes 1. Lieux communs. París: Belin, 2002.

EQuipe MIT. Tourismes 2. Moments de lieux. París: Belin, 2005.

Equipe MIT. Tourismes 3. La révolution durable. París: Belin, 2011.

Fesnau, Vincent. "Le Queyras: entre pays et arrière-pays". Montagnes Méditerranéennes 6 (1997): 91-95.

García de Fuentes, A., S. Jouault, y D. Romero. Atlas de turismo alternativo de la Península de Yucatán. Mérida: Universidad Autónoma de Yucatán y Centro de Investigaciones y Estudios Avanzados (CINVESTAV)-Unidad Mérida, 2015.

Gaztambide-Geigel, Antonio. "La invención del Caribe en el siglo XX. Las definiciones del Caribe como problema histórico y metodológico". Revista Mexicana del Caribe 11 (1996): 75-96.

Giraut, Frédéric. "Pays et arrière-pays. Quelques hypothèses sur la nature et les fonctions contemporaines des arrière-pays de montagnes méditerranéennes". Montagnes Méditerranéennes 6 (1997): 15-18. Girvan, Norman. "Reinterpreting the Caribbean". En The Caribbean Economy, a reader, editado por Pantin. Kingston: Ian Randle Publishers, 2005.

78 Godard, Henry y Thierry Hartog. "Le bassin Caraibe: Présentation". Mappemonde, 724 (2003). http://www.mgm.fr/PUB/Mappemonde/Mappe403R.html 
Guarch-Delmonte, José. “The first Caribbean People”. En General History of the Caribbean, Vol I. Autochtonous Societies, editado por J. Sued-Badillo, London: UNEsCo, 2003, 93-133.

Gumuchian, Henri. "A propos de quelques notions: marges, périphéries et arrière-pays". Montagnes Méditerranéennes 6 (1997): 9-11.

Helion, Christophe y Sylvie Christofle. "Moyen et haut-pays azuréens: l'échec $\mathrm{d}$ une touristification des marges d'un haut-lieu du tourisme mondial, en colloque". En Colloque Tourisme, marge et périphérie, editado por 41 ème journées de la commission de géographie du tourisme et des loisirs. Quimper, 2014..

Instituto Nacional de Estadística y Geografía (INEGI). Anuario estadístico de los Estados Unidos Mexicanos 2014, Ciudad de México: INEGI, 2014. http://internet.contenidos.inegi.org.mx/contenidos/ productos/prod_serv/contenidos/espanol/bvinegi/productos/ anuario_14/702825066482.pdf

Instituto Nacional de Estadística y Geografía (INEGI). Censo Nacional de Población y Vivienda : INEGI, 2010 http://www.inegi.org.mx $>$ Estadistica

Instituto Nacional de Estadística y Geografía (INEGI). Encuesta Intercensal 2015, Ciudad de México: INEGI 2015. http://www.beta. inegi.org.mx/proyectos/enchogares/especiales/intercensal/

Jouault, Samuel, Ana García de Fuentes y Tlacaelel Rivera. "Modelo Regional de Turismo Alternativo y Economía Social en la Península de Yucatán, México". Otra Economía 917 (2015):164-176.

Jouault Samuel., Ana García de Fuentes y Marcela Jiménez. "L’arrière-pays touristique de Cancún Riviera Maya". En Tourisme, marges et périphéries, editado por N. Bernard, C. Blondy y P. Duhamel. Rennes: Presses Universitaires de Rennes, 2017, 233-252.

Kempado, Kamala (editor). Sun, Sex and Gold, Tourism and Sex Work in the Caribbean. New York: Rowman \& Littlefield Publishers, 1999.

Knafou, Rémy. Atlas de France. París: La Documentation Française, 1997.

Knafou, Rémy. "L'invention du lieu touristique: la passation d'un contrat et le surgissement simultané d'un nouveau territoire". Revue de géographie alpine 4 (1991): 11-19. 
Knafou, Rémy, M. Bruston, F. Deprest, P. Duhamel, J.C. Gay y I. Sacareau. "Une aproche géographique du tourisme". L'Espace Géographique 263 (1997): 193-204.

Knafou, Rémy, y M. Stock. "Épistémologie de la géographie" en Dictionnaire de la géographie et de l'espace des sociétés, editado por J. Levy y M. Lussault. París: Belin, 2003, 323-325.

Levy, Jacques y Michel Lussault. Dictionnaire de la géographie et de l'espace des sociétés. París: Belin, 2003.

Lew, Alan. y McKercher, Bob. "Modeling tourist movements, a local destination analysis". Annals of Tourism Research, Vol. 33, N. 2, pp. 403-423, 2006

$\mathrm{Li}, \mathrm{Lu}$. "Les pratiques tourstiques des touristes francais en Chine". Tesis de doctorado, Université d'Angers, 2012.

Mondou, Véronique y Philippe Violier. Projets, pratiques et lieux touristiques, quelles relations? Angers: Université d'Angers, 2004.

Organización Mundial del Turismo (Омт). Barómetro OMT del Turismo Mundial. Departamento de publicaciones del OMT, 2010. http://cf.cdn.unwto.org/sites/all/files/pdf/unwto_barom10_3_ sp.pdf

Organización Mundial del Turismo (OMT). Panorama OMT del Turismo Internacional. Departamento de publicaciones de la OMT, 2017. https://www.e-unwto.org/doi/pdf/10.18111/9789284419043

Rey, Alain y Josette Rey-Debove. Le Petit Robert: dictionnaire de la langue française. París: Éditions Le Robert, 2009.

Rodriguez, José Mateo. “Qu'est ce que la Caraibe? Vers une définition géographique". En Caribbean Atlas, editado por Cruse y Rhiney, 2013. http://www.caribbean-atlas.com/fr/thematiques/quest-ceque-la-caraibe/qu-est-ce-que-la-caraibe-vers-une-definition-geographique/.

Roux, Emmanuel. “La vallée de la Haute-Bléone, arrière-pays d'un pays dignois en construction?". Montagnes Méditerranéennes 6 (1997): 77-82.

Sheller, Mimi. Consuming the Caribbean, from Arawaks to Zombies. London y New York: Routledge, 2003.

Simon, Gwendal. Pratiques touristiques dans la métropole parisienne: une analyse des mouvements. París: Université Paris-Est, 2010. 
Stock, Mathis y Philippe Duhamel. "A practice-based approach to the conceptualisation of geographical mobility". Belgium Journal of Geography 1-2 (2004): 59-68.

Suchet, André. y Anton-Clave, Salvador. "A-t-on vraiment besoin du concept d'arrière-pays en géographie du tourisme?" En Colloque Tourisme, marge et périphérie, editado por 41ème journées de la commission de géographie du tourisme et des loisirs. Quimper, 2014.

Urry, John. The Tourist Gaze: Leisure and Travel in. Londres: Sage publications, 1990.

Vigarie, Alain. Ports de commerce et vie littorale. París: Hachette, 1979.

Vigarie, Alain. "L'évolution de la notion d'arrière-pays en économie portuaire". Transports 428 (2004): 372-387.

Violier, Philippe. "Tourisme et médias: regards d'un geografe". Le Temps des Médias 8 (2007): 159-170.

Wood, Yolanda. "Repensar el espacio Caribe". Revista de la Universidad de La Habana. 236 (1989): 67-80.

Weaver, David. "A broad context model of destination development scenarios". Tourism Management 21 (2000) 217-224.

Para citar este artículo: Jouault, Samuel. "Las movilidades y prácticas turísticas ¿criterios válidos para delimitar el Caribe continental? Reflexiones a partir del caso de Yucatán”, Historia Caribe Vol. XV No. 37 (Julio-Diciembre 2020): 51-81 DOI: http://dx.doi.org/10.15648/ hc.37.2020.4 